Publisher homepage: www.universepg.com, ISSN: 2663-6913 (Online) \& 2663-6905 (Print)

https://doi.org/10.34104/ajpab.022.01009

American Journal of Pure and Applied Biosciences

Journal homepage: www.universepg.com/journal/ajpab

\title{
Prediction of Compaction Parameters from Soil Index Properties Case Study: Dam Complex of Upper Atbara Project
}

\author{
Abusamra A. A. Yousif ${ }^{1,2 *}$ and Mohamed I. A. ${ }^{3}$ \\ ${ }^{1}$ Civil Engineering Program, Albaha University, Albaha, Saudi Arabia; ${ }^{2}$ Dept. of Civil Engineering Omdurman Islamic \\ University, Omdurman, Sudan; ${ }^{3}$ Ministry of Electricity and Dams, Dams Implementation Unit, Dam complex of the \\ upper Atbara project, Showak, Sudan. \\ *Correspondence: Ayousif@bu.edu.sa (Abusamra A. A. Yousif, Assistant Professor, Civil Engineering Program, Albaha \\ University, Albaha, Saudi Arabia).
}

\begin{abstract}
Soil compaction involves concretion and a relative variation of physical and mechanical properties of soils. Determining laboratory compaction characteristics such as maximum dry density (MDD) and optimum moisture content (OMC) could be vital work to manage field compaction for all earth-works structures. There are 3 necessary Atterberg limits: plastic limit (PL), liquid limit (LL), and Plastic Index (PI). The most objective of this paper is to get the relationships between compaction parameters and their Atterberg limits of fine-grained soils and to create reliable correlations. For conducting this work, forty samples are collected from a borrowed space that is found at the bank upstream of Setit watercourse. The tests of soil samples were executed at the laboratory of Dam complex of the upper Atbara project. To perform this work, the Microsoft Office Excel software was exercised for the regression analysis of compaction parameters and Atterberg limits. Several trials were created to get the relationships between Atterberg limits (LL, PL, and PI) with the compaction parameters (OMC, and MDD). From the regression analysis, it's found that OMC and MDD have an excellent relationship with the LL other than the PL and PI. It had been observed that the (OMC) has an excellent correlation with (MDD) other than the remaining parameters. From this work, it's going to be suggested to use the soil compaction properties and Liquid Limits' correlations attributable to their reliable results compared with the other correlations. The result of the paper may be helpful and applicable in numerous civil engineering sectors, particularly for preliminary investigations and prefeasibility studies of various civil engineering works.
\end{abstract}

Keywords: Liquid limit, Plastic limit, Plasticity index, Optimum moisture content, and Maximum density.

simpler and quicker method of testing, the engineering properties can be predicted using empirical correlations (Nerea, 2012). The study of Soil compaction is the most vital engineering technique generally applied in various civil engineering fields. The purpose of the soil compaction is to improve the soils' properties that lead to increase their shear strength and bearing capacity (ATSBEHA 2013).

The crucial step in controlling the field compaction associated with earthworks is to find compaction characteristics from laboratory tests (Farooq, Khalid et al., 2016). However, throughout the first stages of UniversePG I www.universepg.com

\section{INTRODUCTION:}

Safety and stability are important for every structure resting on the ground. To obtain these safety and stability requirements, the soil characteristics should be identified. However, requiring more time and money to obtain the soil's properties of soils. Really, investigating the compaction characteristics of soil is much easier than investigating other engineering characteristics; in terms of time, money, and effort. Moreover, most characteristics of soils depend upon their index properties. Therefore, by obtaining the compaction characteristics of soils that involve a 
the particles decrease. It can, therefore, improve the soil properties. This can lead to the increment of shear strength and modification of volume amendment characteristics (Ali et al., 2019). The soil compaction parameters have a great effect on obtaining the target engineering properties of soil during construction. Standard compaction tests are the most vital laboratory test methods to determine the soil's compaction characteristics. Estimated achievements were done in the past to correlate the soil compaction parameters (Khalid and Rehman, 2018). Another work developed prediction models for compaction parameters of soils in Ceará, Brazil, depending on the index and physical properties.

The methodology enclosed knowledge from soils utilized in the development of fifteen dams in Ceará, with obtained information concerning laboratory tests of interest (Vieira et al., 2022). The optimal dry density and optimum moisture content obtained from the Proctor results were very significant for geotechnical engineering. Because the Proctor take a look at is comparatively time-consuming and laborious, in this work neural network is employed to estimate the compaction parameters of soils indirectly from additional determined index properties like (LL), (PL), and fine-grained content in addition as sand content (Ardakani, et al., 2019). Previous prediction models for soil compaction characteristics were expanded using limited data of specific soil sand their accuracy also needs to be improved. The development of a new prediction model for the soil compaction characteristics using multi-expression programming was offered (Wang and Yin, 2020).

\section{Objectives of the Study}

The objectives of this paper are summarized as follows:

1) To obtain usable relationships between Atterberg limits and compaction parameters of fine-grained samples collected from Dam complex of upper Atbara project borrow space.

2) To know the significance of soil laboratory tests that is $\mathrm{d}$ for big projects.

\section{METHOLODOGY:}

Sources include books, journals, scientific papers, standards, and online material from the internet. It is from the literature focus that the conceptual and methodological background of the entire research was established. The methodology is based on laboratory evaluation of characteristics of the soil. They UniversePG I www.universepg.com a project (e.g., within the preliminary assessment of the suitableness of borrow materials), the right smart time and effort will be saved through the utilization of empirical correlations, which might be very useful, on condition that the engineer is aware of the index properties of the soil. Index properties are those upon that the identification and classification steps of soil are based; this includes grain-size distribution, Atterberg limits, density, and relative density (Gurtug et al., 2004; Sridharan and Nagaraj, 2005; Bigotti et al., 2009; Günaydın, 2009; Chenari et al., 2015). The compaction characteristics are determined through very time-consuming laboratory tests. The prediction compaction parameters are based on easily measurable soil properties highly utilized and more useful (Karimpour et al., 2019). Omar et al. (2003) collected 311 samples of sandy and sandysilty soils from the United Arab Emirates and performed laboratory tests. They developed a rectilinear regression model to predict soil compaction parameters for modified Proctor energy using fines percentage, (LL), (PL), and compaction energy. Their model resulted in nomograms capable of predicting OMC and MDD for granular soils at intervals of a ninety-fifth confidence interval for the analyzed samples (Omar et al., 2003). Sridharan and Nagaraj, (2005) expressed that the relationships provided at the time between index properties and compaction parameters were inadequate.

They analyzed ten soil samples (natural and trade kaolinites) and knowledge provided within the literature, finding that PL had a higher correlation with compaction parameters than (LL) and also the (PI) for Standard Proctor compaction effort (Sridharan and Nagaraj 2005). Toms and Prince Philip (2016) performed regression analysis with multiple variables to predict compaction parameters from Atterberg limits and specific unit weight for thirty soil samples from Kuttanad, India, with LL travel between seventy and one hundred and ninetieth, PI between 26 and $127 \%$, and specific unit weight between 2.3 and $2.5 \mathrm{kN} / \mathrm{m}^{3}$. They complete that there's the spot linear relationship between index properties and compaction parameters which the foremost vital variables were relative density and index properties (Toms and Philip, 2016). Soil compaction could be a basic method to develop soil stability. It is often performed using mechanical force to pack soil particles nearer. Soil compaction participates in increasing the density of soil because the voids between 
Samples extracted from the different sites were sieved over a $4.75 \mathrm{~mm}$ sieve for testing and compacted in a $105 \mathrm{~mm}$ - diameter mold as described in Procedure of the BS 1377 Part 4. Each sample was directly tested out for moisture content as stated by ASTM D-2216; the moisture content obtained from this process was used for the generation of a compaction curve. Finally, the (MDD) and the corresponding (OMC) were computed using spreadsheet and chart plots.

\section{e. Organic Matter}

The clay material (Zone 1) of the earth core rockfill dam shall consist of a material with an organic matter content of less than $3 \%$, as stated by the ASTM D-2974.

\section{f. Permeability}

The clay material (Zone 1) of the earth core rockfill dam shall consist of a material with a permeability coefficient of less than $10-7 \mathrm{~m} / \mathrm{s}$ after compaction. The permeability coefficient shall be determined on samples from the compacted embankment and extracted by the drive-cylinder method. Whole tests were performed at the dam complex of the upper Atbara project in two groups. The first group results (20 samples) from Borrow Area, BU3-QF for all pits were illustrated in Table 1. The second group result (20 samples) for four pits in BU3-QF Borrow Area was illustrated in Table 2.

Table 1: Laboratory Test Results for First Group. were obtained from borrowed areas of the Dam complex of the upper Atbara project. The samples used were obtained primary data for this work are taken from Borrow Area BU3-QF, which is located at the right bank upstream of Set it River, with an elevation of $520.00 \mathrm{~m}$ above Alexandria Mean Sea Level. This borrows space served because the major supply of core materials for Burdana dyke and dam construction. The quantity of (BU3-QF) is about 974 $550.00 \mathrm{~m}^{3}$. The soil tests accomplished are listed as follows:

\section{a. Grain Size Analysis}

The amount of soil materials finer than $0.075 \mathrm{~mm}$ was determined using T.S, section 02222, 1.3.3, a method for the amount of material in the soil finer than the No. 200 sieve (Uddin et al., 2017).

\section{b. Atterberg Limits}

The LL, Pl, and PI were specified according to technical specification, DCUAP Contract Test Method (T.S, section 02222, 1.3.3), and BS 1377 Part 2.

\section{c. Specific Gravity}

For each type of soil, it was specified according to BS1377 Part 2 (Standard Test Method for Specific Gravity of Soils). The precision and bias of each pair of tests were investigated and all are within the BS accepted range.

\section{d. Moisture-Density Relationship}

\begin{tabular}{|c|c|c|c|c|c|c|c|c|}
\hline \multirow{2}{*}{ Test No. } & \multirow{2}{*}{ Borehole No. } & \multirow{2}{*}{ Depth $(\mathbf{m})$} & \multirow{2}{*}{ Gs $\left(\mathbf{g} / \mathbf{c m}^{\mathbf{3}}\right)$} & \multicolumn{3}{|c|}{ Atterberg limits } & \multicolumn{2}{c|}{ Compaction Test } \\
\cline { 5 - 8 } & & & $\mathbf{L L \%}$ & $\mathbf{P L \%}$ & $\mathbf{P I \%}$ & OMC\% & MDD $\left(\mathbf{g} / \mathbf{c m}^{\mathbf{3}}\right)$ \\
\hline 1 & $1-3-1$ & $1.5-5.5$ & 2.76 & 37 & 20 & 17 & 22.5 & 1.59 \\
\hline 2 & $1-3-2$ & $1.5-5.5$ & 2.78 & 35 & 21 & 14 & 22.6 & 1.59 \\
\hline 3 & $2-1-1$ & $0-0.8$ & 2.77 & 50 & 20 & 30 & 24.5 & 1.54 \\
\hline 4 & $2-1-2$ & $0-0.8$ & 2.79 & 55 & 22 & 33 & 25.0 & 1.53 \\
\hline 5 & $4-5-6$ & $1.5-6.5$ & 2.80 & 46 & 22 & 24 & 21 & 1.62 \\
\hline 6 & $7-1-1$ & $0-1.4$ & 2.76 & 68 & 26 & 42 & 29.0 & 1.44 \\
\hline 7 & $8-1-1$ & $0-1.2$ & 2.81 & 59 & 19 & 40 & 23.5 & 1.52 \\
\hline 8 & $10-1-1$ & $0-4$ & 2.72 & 43 & 19 & 24 & 22.9 & 1.58 \\
\hline 9 & $10-1-2$ & $0-4$ & 2.74 & 44 & 21 & 23 & 23.1 & 1.56 \\
\hline 10 & $11-1-1$ & $0-1$ & 2.79 & 32 & 16 & 16 & 23.5 & 1.60 \\
\hline 11 & $11-1-2$ & $1-2$ & 2.77 & 30 & 16 & 14 & 24.0 & 1.60 \\
\hline 12 & $13-2-1$ & $0-1$ & 2.77 & 35 & 18 & 17 & 24 & 1.61 \\
\hline 13 & $14-6-1$ & $0-1$ & 2.79 & 37 & 14 & 23 & 23.5 & 1.58 \\
\hline 14 & $14-6-2$ & $1-2$ & 2.77 & 39 & 15 & 24 & 23.7 & 1.59 \\
\hline 15 & $15-6-1$ & $3-4$ & 2.78 & 63 & 21 & 42 & 26.0 & 1.51 \\
\hline 16 & $16-2-1$ & $0-1.2$ & 2.75 & 66 & 26 & 40 & 30.0 & 1.40 \\
\hline 17 & $17-1-1$ & $0-2$ & 2.75 & 68 & 25 & 43 & 26.3 & 1.46 \\
\hline 18 & $17-1-2$ & $2-4$ & 2.76 & 69 & 25 & 44 & 25.8 & 1.52 \\
\hline 19 & $18-1-1$ & $0-1.7$ & 2.75 & 67 & 26 & 41 & 28.0 & 1.48 \\
\hline 20 & $18-1-2$ & $0-1.7$ & 2.75 & 62 & 23 & 39 & 27.0 & 1.48 \\
\hline
\end{tabular}


Table 2: Laboratory Test Results for Second Group.

\begin{tabular}{|c|c|c|c|c|c|c|c|c|}
\hline \multirow{2}{*}{ Test No. } & \multirow{2}{*}{ Borehole No. } & \multirow{2}{*}{$\operatorname{Depth}(\mathrm{m})$} & \multirow{2}{*}{ Gs $\left(\mathrm{g} / \mathrm{cm}^{3}\right)$} & \multicolumn{3}{|c|}{ Atterberg limits } & \multicolumn{2}{|c|}{ Compaction Test } \\
\hline & & & & LL\% & PL\% & PI\% & OMC\% & $\operatorname{MDD}\left(\mathrm{g} / \mathrm{cm}^{3}\right)$ \\
\hline 1 & $10-1-1$ & $0-4$ & 2.72 & 43 & 19 & 24 & 22.9 & 1.58 \\
\hline 2 & $10-1-2$ & $0-4$ & 2.74 & 44 & 21 & 23 & 23.1 & 1.56 \\
\hline 3 & $10-1-3$ & $0-4$ & 2.75 & 42 & 20 & 22 & 24.8 & 1.59 \\
\hline 4 & $10-1-4$ & $0-4$ & 2.72 & 40 & 19 & 21 & 24.6 & 1.59 \\
\hline 5 & $10-1-5$ & $0-4$ & 2.74 & 39 & 18 & 21 & 24.5 & 1.61 \\
\hline 6 & $10-1-6$ & $0-4$ & 2.75 & 37 & 18 & 19 & 23.9 & 1.58 \\
\hline 7 & $10-1-7$ & $0-4$ & 2.79 & 36 & 18 & 18 & 22.4 & 1.61 \\
\hline 8 & $10-1-8$ & $0-4$ & 2.78 & 39 & 18 & 21 & 22.7 & 1.60 \\
\hline 9 & $1-3-1$ & $1.5-5.5$ & 2.76 & 37 & 20 & 17 & 22.5 & 1.59 \\
\hline 10 & $1-3-2$ & $1.5-5.5$ & 2.78 & 35 & 21 & 14 & 22.6 & 1.59 \\
\hline 11 & $2-1-1$ & $0-0.8$ & 2.77 & 50 & 20 & 30 & 24.5 & 1.54 \\
\hline 12 & $2-1-2$ & $0-0.8$ & 2.79 & 55 & 22 & 33 & 25.0 & 1.53 \\
\hline 13 & $2-1-3$ & $0-0.8$ & 2.77 & 58 & 22 & 36 & 25.7 & 1.53 \\
\hline 14 & $2-7-1$ & $0-1$ & 2.79 & 53 & 21 & 32 & 25.5 & 1.54 \\
\hline 15 & $2-7-2$ & $0-1$ & 2.78 & 54 & 19 & 35 & 24.0 & 1.54 \\
\hline 16 & $2-7-3$ & $0-1$ & 2.78 & 57 & 22 & 35 & 25.5 & 1.49 \\
\hline 17 & 18-1-1 & $0-1.7$ & 2.75 & 67 & 26 & 41 & 28.0 & 1.48 \\
\hline 18 & $18-1-2$ & $0-1.7$ & 2.75 & 62 & 23 & 39 & 27.0 & 1.48 \\
\hline 19 & $18-2-1$ & $0-1.4$ & 2.73 & 70 & 24 & 46 & 26.0 & 1.50 \\
\hline 20 & $18-2-2$ & $0-1.4$ & 2.73 & 63 & 21 & 42 & 27.5 & 1.48 \\
\hline
\end{tabular}

Note: $\mathrm{LL}=$ Liquid limit, PL = Plastic Limit, PI = plasticity Index, MDD = Maximum Dry Density, OMC = Optimum Moisture Content, $\mathrm{G}_{\mathrm{s}}=$ Specific Gravity.

between the MDD and PL is the weakest in comparison with other Atterberg limits as illustrated in Fig. 6. In addition, MDD has the best relationship with OMC than all other parameters. Thus, it was also predicted that MDD OMC more accurately than LL versus the OMC. The relationship between the dependent and independent variables is checked separately for the second Group data as illustrated in Fig. 9-16. Similarly, the regression of OMC and Atterberg limits for the second group were checked as shown in Fig. 9-12.

The OMC has an excellent correlation with LL than PL, PI. On the other hand, the relationship between the OMC and PL is the weakest in comparison with the other Atterberg limits as illustrated in Fig. 10. It was noticed that OMC has the best relationship with MDD than all other para-meters. It was observed that the LL has an excellent relationship with MDD. Both OMC and MDD were predicted from LL only with suitable accuracy. As shown in Fig. 13, the relationship between the MDD and PL is the weakest in comparison with the other Atterberg limits. MDD has the best relationship with OMC than all other parameters. Analysis of Results between the first group and the second group are the same.

\section{RESULTS:}

This part describes the discussion of results obtained from Atterberg limits and compaction characteristics of soils. In conducting the statistical analysis, Microsoft Office Excel software was used to determine the scatter plot, correlation, and regression. Excel spreadsheet was established to be the most powerful and handy tool for analyzing scatter plots and determining the correlation between two or more diverse. The relationship between different variables is examined separately for the first group data as presented in Fig. 1-8. It was found that the OMC has an effective correlation with LL than PL, PI. On the other hand, as illustrated in Fig. 1, the relationship between the OMC and PI is the weakest of all the Atterberg limits. As shown Fig. 3, it was observed that the OMC has the best relationship with MDD than all other parameters, as shown in Fig. 4.

In general, it was concluded that the estimation of soil moisture content of over consolidated soils, a compression standard Proctor, can be foreseen from LL without significant error. It was noticed that LL has a valuable relationship with MDD as shown in Fig. 5. Both OMC and MDD were predicted from LL only with acceptable accuracy. The relationship 


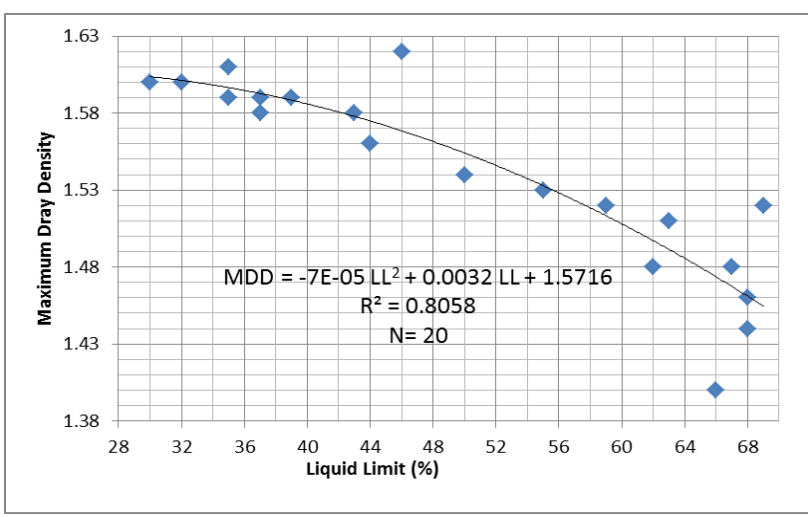

Fig. 5: Regression to fit the Best Curve for LL and MDD.

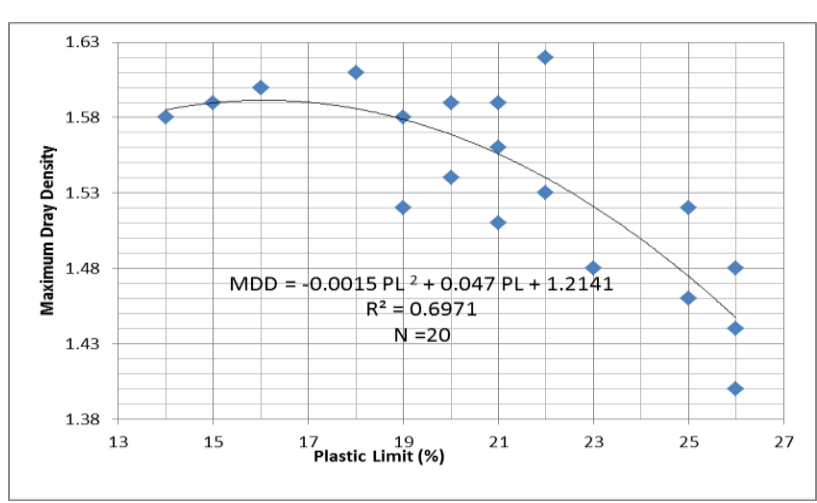

Fig. 6: Regression to fit the Best Curve for PL and MDD.

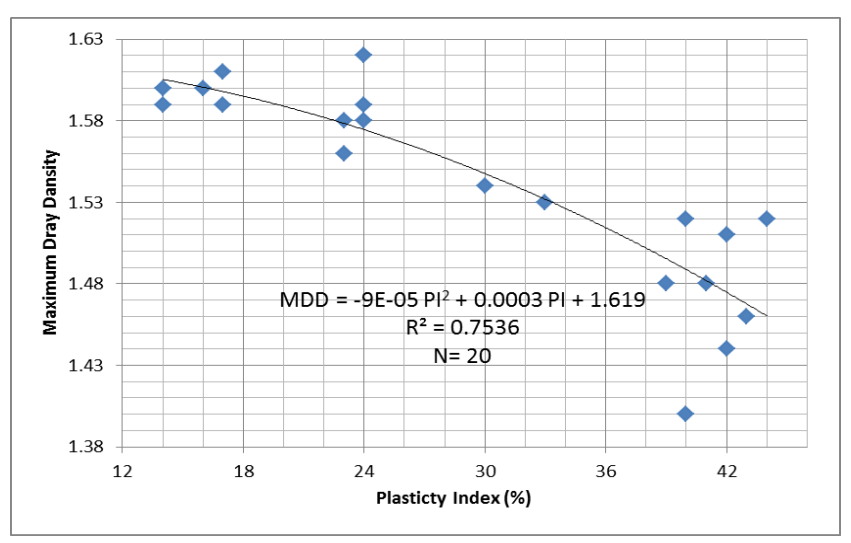

Fig. 7: Regression to fit the Best Curve for PI and MDD.

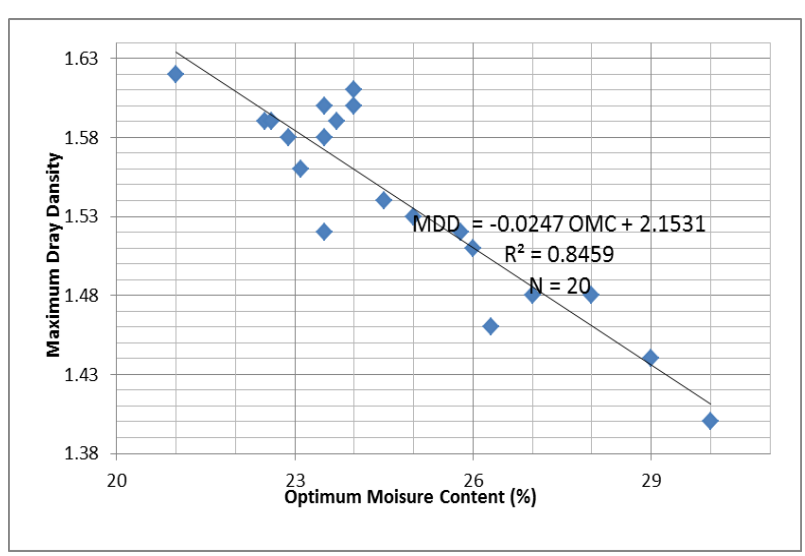

Fig. 8: Linear Regression for OMC and MDD.

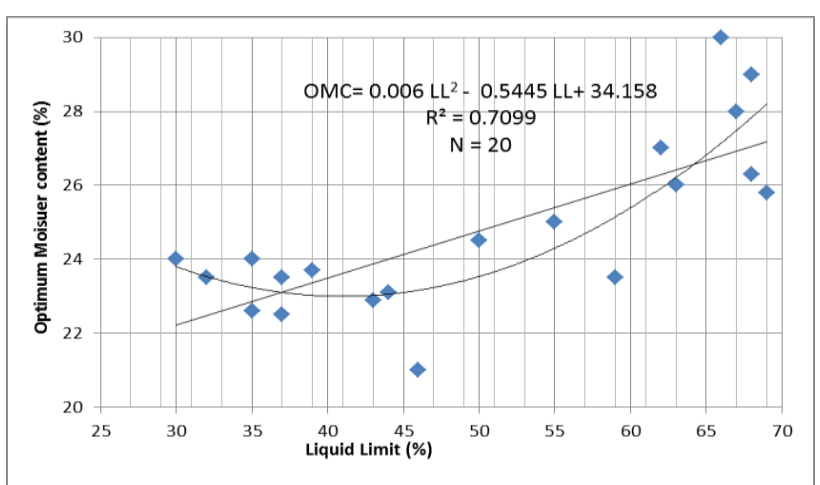

Fig. 1: Regression to fit the Best Curve for LL and OMC.

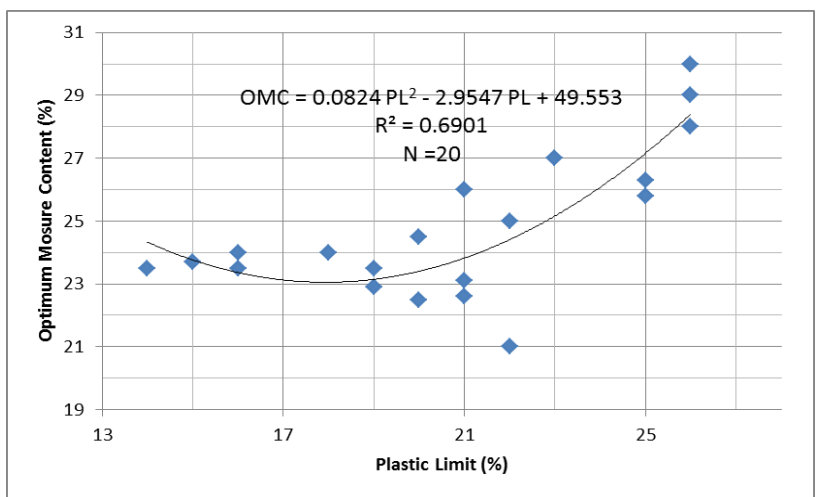

Fig. 2: Regression to fit the Best Curve for PL and $\mathrm{OMC}$.

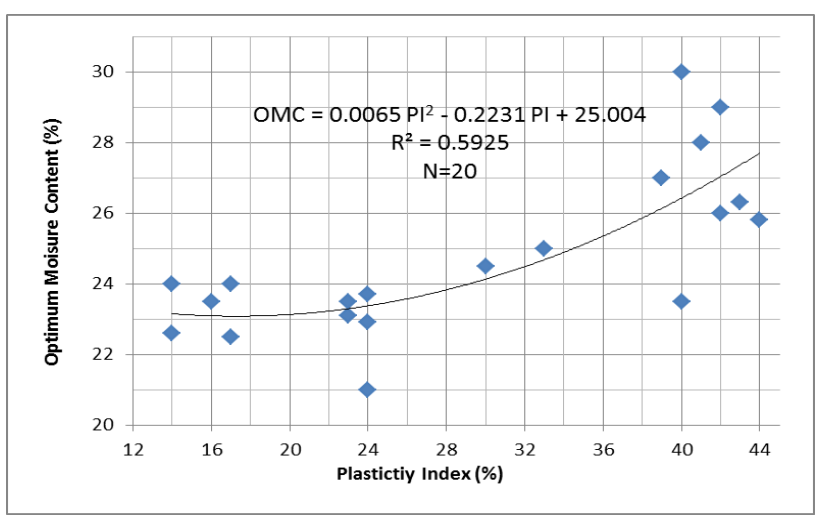

Fig. 3: Regression to fit the Best Curve for PI and OMC.

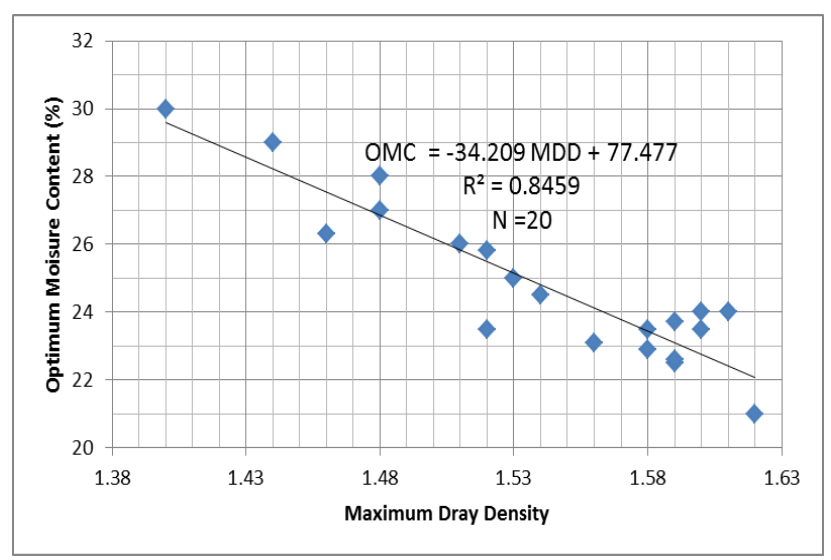

Fig. 4: Linear Regression for MDD and OMC. 


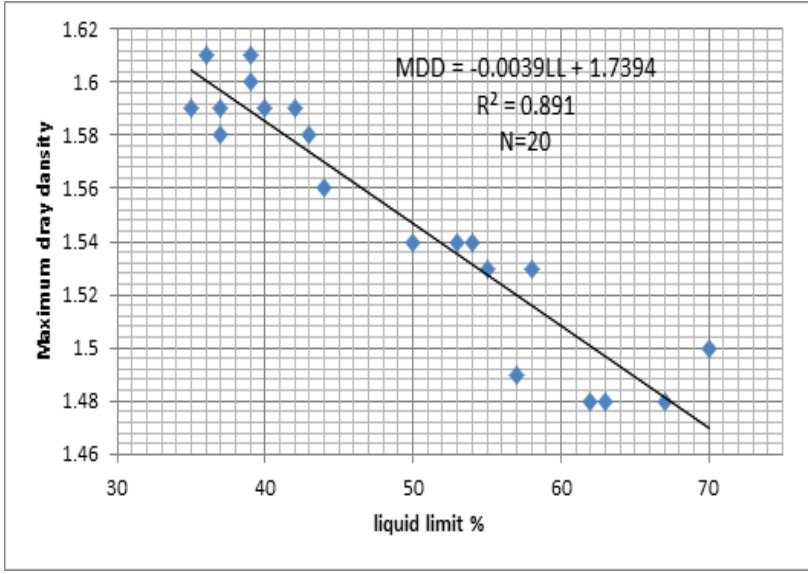

Fig. 13: Linear Regression for LL and MDD.

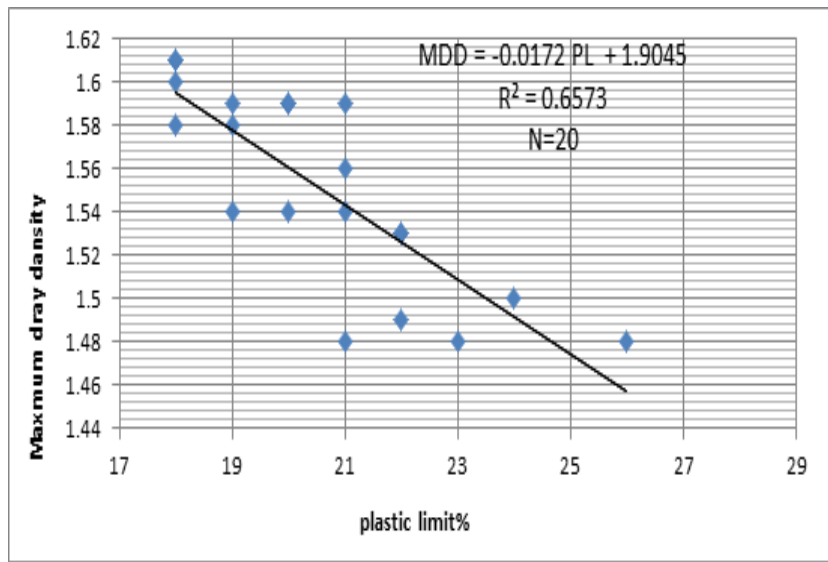

Fig. 14: Linear Regression for PL and MDD.

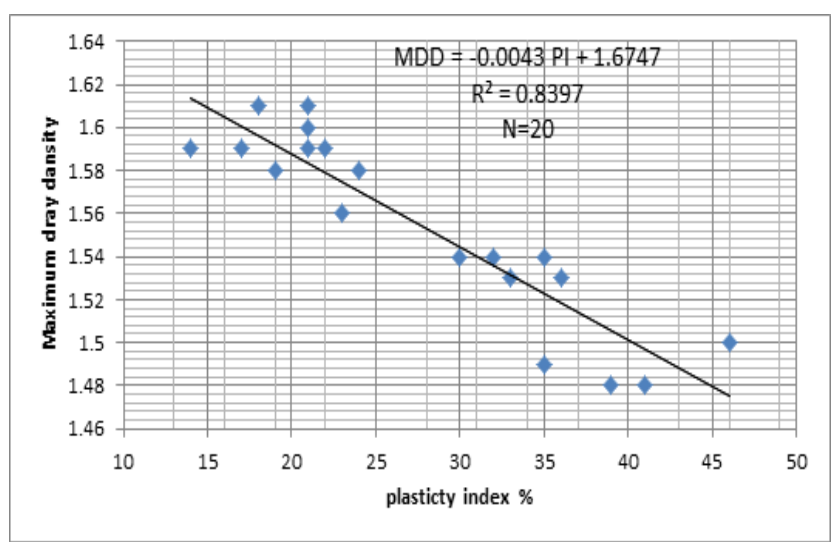

Fig. 15: Linear Regression for PI and MDD.

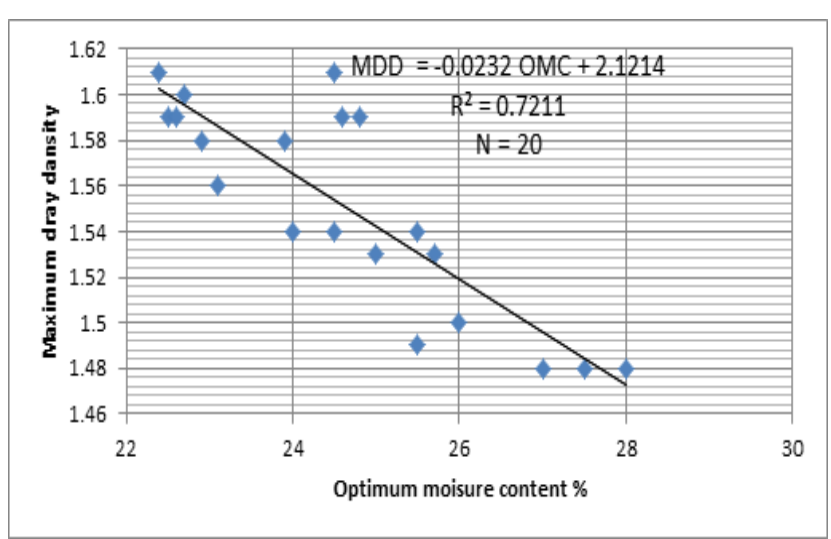

Fig. 16: Linear Regression for OMC and MDD.

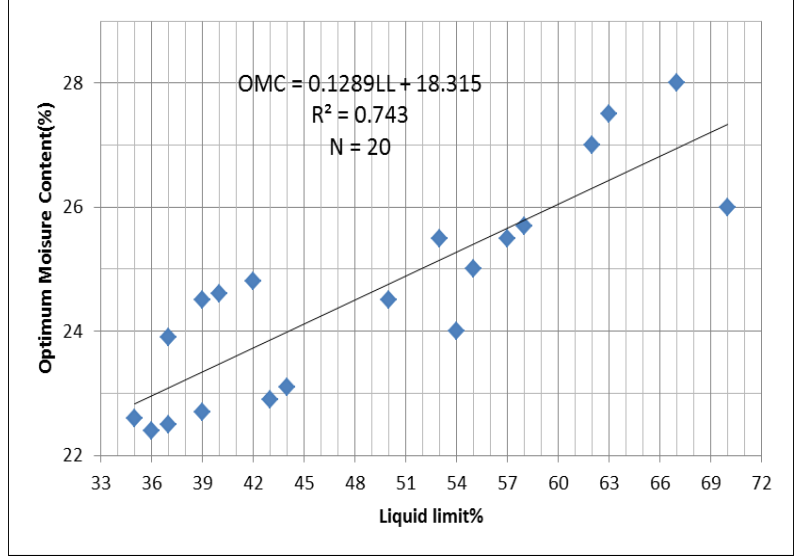

Fig. 9: Linear Regression for LL and OMC.

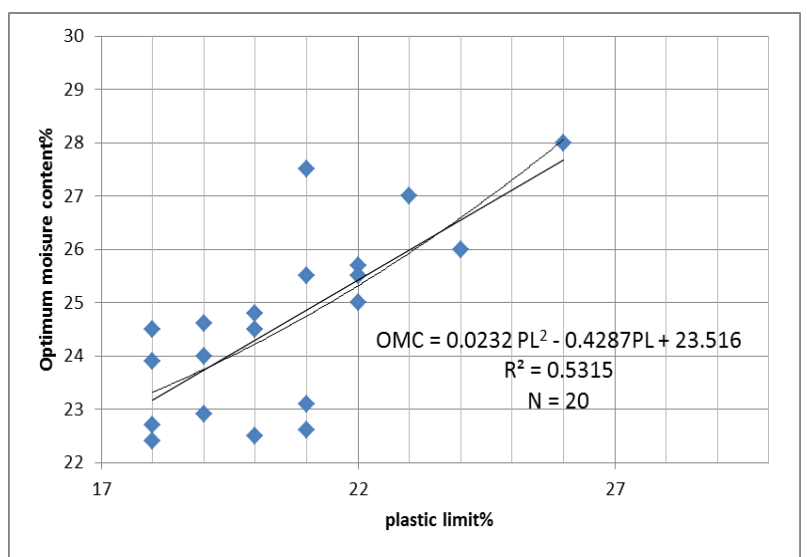

Fig. 10: Linear Regression for PL and OMC.

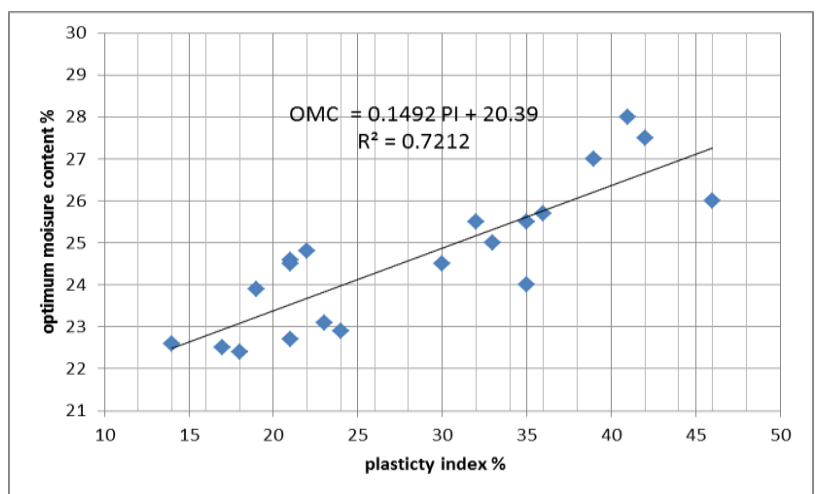

Fig. 11: Linear Regression for PI and OMC.

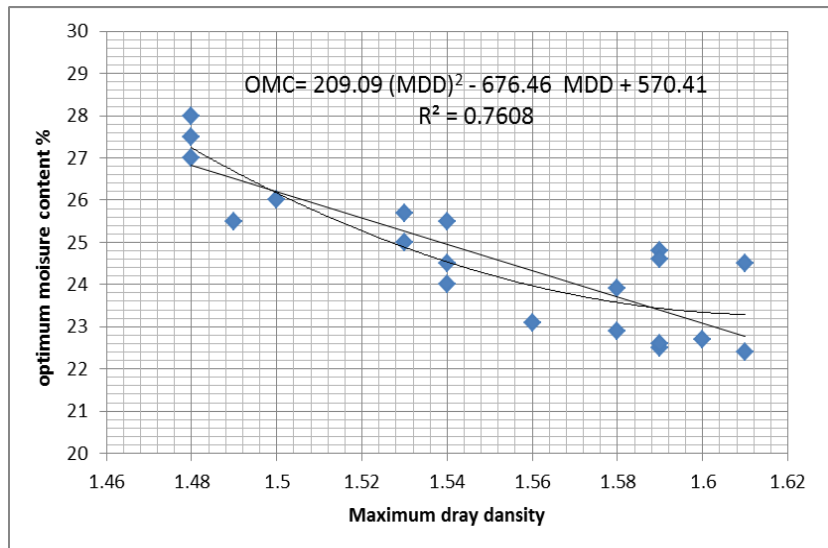

Fig. 12: Linear Regression for MDD and OMC. 
Table 3. It was concluded that compaction parameters of fine-grained soils found by the Proctor test and proposed equations have a strong relationship.
The OMC and MDD have a very good correlation with LL than other Atterberg limits. A comparison between OMC and MDD Obtained by the proctor and by the proposed equations was presented in

Table 3: A Comparison Between OMC and MDD obtained by Proctor Test and Proposed Equation.

\begin{tabular}{|c|c|c|c|c|}
\hline \multirow{2}{*}{ No. } & \multicolumn{2}{|c|}{ OMC (\%) } & \multicolumn{2}{c|}{ MDD $\left(\mathbf{g} / \mathbf{c m}^{\mathbf{3}}\right)$} \\
\hline $\mathbf{1}$ & By Proctor & By proposed Equation & By Proctor & By proposed Equation \\
\hline $\mathbf{2}$ & 22.5 & 23.05 & 1.59 & 1.60 \\
\hline $\mathbf{3}$ & 24.5 & 23.43 & 1.54 & 1.55 \\
\hline $\mathbf{4}$ & 29.0 & 27.1 & 1.44 & 1.47 \\
\hline $\mathbf{5}$ & 25.0 & 24.45 & 1.40 & 1.41 \\
\hline $\mathbf{6}$ & 22.9 & 23.8 & 1.60 & 1.58 \\
\hline $\mathbf{7}$ & 24.5 & 23.32 & 1.58 & 1.57 \\
\hline $\mathbf{8}$ & 27.0 & 26.21 & 1.61 & 1.59 \\
\hline
\end{tabular}

itional variables. The discussion of regression analysis was summarized as follows:

a) In the first group, it was found that the (OMC) has a strong correlation with LL and the weakest correlation with PL. In addition, (MDD) has also a strong correlation with the (LL) than the other Atterberg limits. Thus, both OMC and MDD have a very good relationship with (LL) than the (PL) and (PI). It was concluded that both OMC and MDD were predicted from the correlation equations without significant errors. However, it should be noted that the (OMC) has the strongest correlation with (MDD) than all other parameters.

b) In the second group, it was noticed that the OMC has a strong correlation with (LL) and has the weakest correlation with (PL). In addition, (MDD) has also a strong correlation with the (LL) than the other Atterberg limits. Thus, both OMC and MDD have a good relationship with the (LL) than the (PL), and the (PI).

c) It was observed that both OMC and MDD may be predicted from the correlation equations without significant errors. However, it was noted that the (OMC) has the strongest correlation with (MDD) than all other parameters.

d) Therefore, it was recommended that both OMC and MDD should be predicted from (LL) without significant reduction in the correlation coefficient, instead of using two or more independent variables, since the value of the regression coefficient is almost the same in both cases.
The comparison between OMC and MDD obtained by Proctor tests and by the proposed equations has a very good relationship as illustrated in Fig. 17- 18.

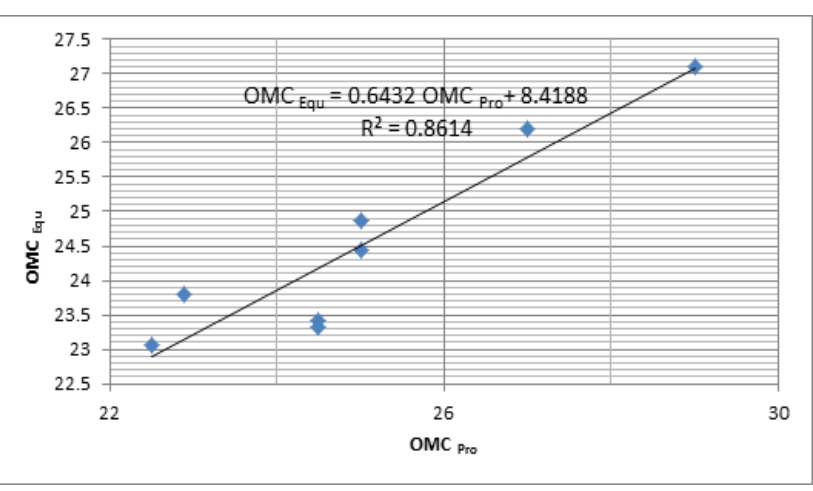

Fig. 17: Linear Regression for $\mathrm{OMC}_{\mathrm{pro}}$ and $\mathrm{OMC}_{\mathrm{Equ}}$.

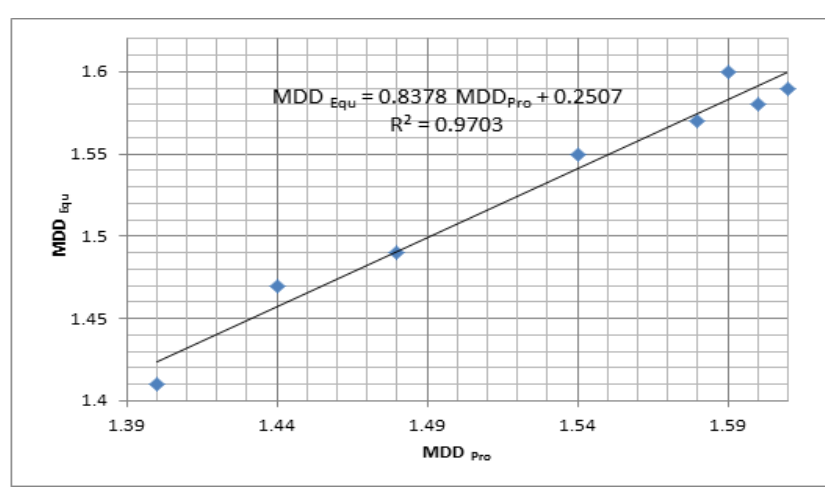

Fig. 18: Linear Regression for $M D D_{\text {pro }}$ and $M D D_{\text {equ }}$

\section{DISCUSSION:}

The regression analysis leads to predicting the OMC and MDD of first and second groups' knowledge from the corresponding Atterberg limits severally were conferred. An endeavor is ready to get that one in all the predictors will be powerfully associated with dependent variables. This has been done by predicting the OMC and MDD from one or add- 


\section{ACKNOWLEDGEMENT:}

We are so much acknowledged Professor Dr. Gafar Ahmed Elnawrani for his guidance in this research.

\section{CONFLICTS OF INTEREST:}

The authors declare that they have no competing interests concerning the research.

\section{REFERENCES:}

1) Ali, H. F. H., A. J. H. Rash and D. A. J. P. J. Muhedin, (2019). "A Correlation between Compaction Characteristics and Soil Index Properties for Fine-grained Soils.", polytechnic journal, 9(2), 93-99.

https://doi.org/10.25156/ptj.v9n2y2019.pp93-99

2) Ardakani, A., A. J. E. J. o. E. Kordnaeij, (2019). "Soil compaction parameters prediction using GMDH-type neural network and genetic algorithm.", 23(4), 449-462.

https://doi.org/10.1080/19648189.2017.1304269

3) ATSBEHA, N. (2013). Predicition of Compaction Charcteristics From Atte-bergLimits For Fine- Grained Soils, Addis Ababa University.

4) Di Matteo, L., F. Bigotti, R. J. J. o. g. Ricco and g. engineering, (2009). "Best-fit models to estimate modified proctor properties of compacted soil." 135(7), 992-996.

https://doi.org/10.1061/(ASCE)GT.1943-5606. 0000022

5) Farooq, K., U. Khalid, H. J. A. J. f. s. Mujtaba, (2016). "Prediction of compaction characteristics of fine-grained soils using consistency limits." , 41(4), 1319-1328.

https://scholar.google.com/citations?view op=vi ew_citation\&hl=en\&user=EtBKKJUAAAAJ\&al ert_preview_top_rm=2\&citation_for_view=EtB KKJUAAAAJ:3fE2CSJIr18C

6) Günaydın, O. J. E. G. (2009). "Estimation of soil compaction parameters by using statistical analyses and artificial neural networks.", 57(1), 203. https://doi.org/10.1007/s00254-008-1300-6

7) Gurtug, Y., A. J. S. Sridharan and foundations, (2004). "Compaction behavior and prediction of its characteristics of fine-grained soils with particular reference to compaction energy.", 44(5), 27-36.

http://eprints.iisc.ac.in/id/eprint/17451

8) Karimpour-Fard, M., S. L. Machado, A. Falamaki, M. F. Carvalho, P. J. I. J. o. S. Tizpa and T. o. C. E. Technology, (2019). "Pre- e) If the soil is compacted at OMC, the particles get lubricated and move easily into a close state position and the corresponding dry unit weight is higher. The specific (OMC) of fine-grained soil is too close to LL. In addition, as the fine content of soil increases, both OMC and LL are increased but MDD is reduced. This condition might be the possible reason that the OMC and MDD have a good correlation with the liquid limit.

f) The comparison between OMC and MDD obtained by the proctor test and the proposed equations has a very good relation.

\section{CONCLUSION:}

Conclusions can be drawn based on the laboratory test results and regression analysis. Both (OMC) and (MDD) of fine-grained soils have better correlations with (LL) than the other Atterberg Limits. The (MDD) has a satisfactory correlation with (LL) and the best relationship with (OMC). Therefore, both OMC and MDD of soils may be predicted from liquid limit (LL) especially for the pre-feasibility study of projects. It should be noted that the OMC has a stronger correlation with MDD than all other parameters. It was concluded that previous studies of predicting compaction parameters of over-consolidated soils (Husain, 2016) and the case study of Upper Atbara have found that (LL) has a good relationship with (MDD) and (OMC). However, (Nerea, 2012) has found that the (PL) has a stronger relationship with (MDD) and (OMC) more than the (LL) and (PI), which is different from this study. The relationships between compaction parameters and Atterberg limits differ according to the type of soil.

\section{Recommendations}

The following recommendations are suggested for further studies:

1) This work can further be extended to correlate the Atterberg limits with other tests such as the modified Proctor test, California Bearing Ratio (CBR), and Permeability test.

2) When the duration of construction is very large, the number of compaction tests are to be performed is time-consuming. Thus, it is very important to obtain the index property parameters that involve simpler, quicker, and cheaper methods of testing; such parameters could be used for the prediction of compaction characteristics. 
from their index parameters.", 8(5), 29112920.

14) Toms, T. and J. G. J. I. J. S. R. Philip, (2016). "Prediction of compaction characteristics from Atterberg limits and specific gravity for Kuttanad soil." 2319-7064.

15) Uddin M. E., Ahmad T., and Ahammed T. (2017). Thermotolerant extracellular proteases produced by Bacillus subtilis isolated from local soil that representing industrial applications. J. of Pure and Applied Microbiol. 11(2), 733-741.

https://doi.org/10.22207/JPAM.11.2.12

16) Vieira, A., R. F. Leme, F. C. da Silva Filho, T. E. Moura and G. R. L. J. I. e. I. Ayala, (2022). "Empirical Models to Predict Compaction Parameters for Soils in the State of Ceará, Northeastern Brazil.", 42(1),e86328-e86328. https://www.mdpi.com/1996-1073/14/2/326/ pdf

17) Wang, H.-L. and Z.-Y. J. E. G. Yin, (2020). "High-performance prediction of soil compaction parameters using multi expression programming.", 276, 105758. diction of compaction characteristics of soils from index test's results." , 43(1), 231-248.

9) Khalid, U. and Z. J. I. J. o. G.-E. ur Rehman, (2018). "Evaluation of compaction parameters of fine-grained soils using standard and modified efforts." , 9(1), 1-17.

10) Nerea, A. (2012). Prediction of Compaction Characteristics from Atterberg Limits for Finegrained Soils, MSc. Thesis, Department of Civil Engineering, Addis Ababa University, Ethiopia.

11) Omar, M., A. Shanableh, A. Basma, S. J. G. Barakat and G. Engineering, (2003). "Compaction characteristics of granular soils in the United Arab Emirates.", 21(3),283-295. https://doi.org/10.1023/A:1024927719730

12) Sridharan, A. and H. J. P. o. t. i. o. c. e.-g. i. Nagaraj, (2005). "Plastic limit and compaction characteristics of fine-grained soils.", 9(1), 1722.

https://www.academia.edu/19168445/Plastic_1 imit and compaction characteristics of fineg rained_soils

13) Tizpa, P., R. J. Chenari, M. K. Fard and S. L. J. A. J. o. G. Machado, (2015). "ANN prediction of some geotechnical properties of soil

Citation: Yousif AAA., and Mohamed IA. (2022). Prediction of compaction parameters from soil index properties case study: dam complex of upper Atbara project. Am. J. Pure Appl. Sci., 4(1), 01-09. https://doi.org/10.34104/ajpab.022.01009 @) (요요 